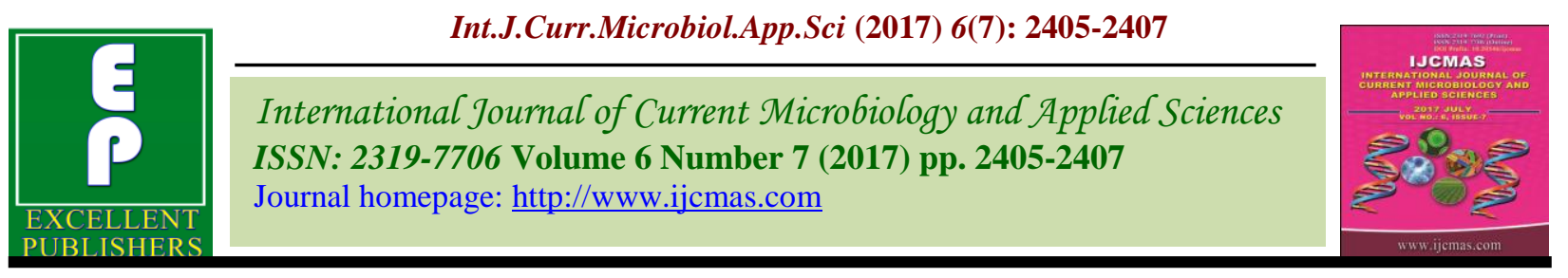

Case Study https://doi.org/10.20546/ijcmas.2017.607.284

\title{
Traditional Crop Management Practices of Central Brahmaputra Valley Zone of Assam, India
}

\author{
B. Gogoi ${ }^{1 *}$, S. Bhagowati ${ }^{2}$ and S. $\operatorname{Das}^{3}$ \\ ${ }^{1}$ Department of Agronomy, ${ }^{2}$ Department of Soil Science, \\ ${ }^{3}$ Department of Horticulture, Krishi Vigyan Kendra, Nagaon, Assam-782002, India \\ *Corresponding author
}

\section{A B S T R A C T}

\begin{tabular}{|c|c|}
\hline Keywords & \\
\hline $\begin{array}{l}\text { Indigenous } \\
\text { technical } \\
\text { knowledge, Wild } \\
\text { animals, Shelf life, } \\
\text { Storage, Pest } \\
\text { management, } \\
\text { Water harvesting. }\end{array}$ & \multirow{3}{*}{$\begin{array}{l}\text { Indigenous technical knowledge is specifically concerned with actual } \\
\text { application of the thinking of the local people in various operations of } \\
\text { agriculture and allied areas. Some of the practices are very common } \\
\text { amongst the community and few vary depending upon the climatic } \\
\text { situations and culture. This paper is based on a study carried out through } \\
\text { interview, Participatory Rural Appraisal and questionnaires for collection } \\
\text { of various information on indigenous technical knowledge (ITK) used for } \\
\text { long term storage and pest management prevalent among the farmers of } \\
\text { Nagaon and Morigaon districts of central Brahmaputra valley zone of } \\
\text { Assam. }\end{array}$} \\
\hline Article Info & \\
\hline $\begin{array}{l}\text { Accepted: } \\
\text { 23 June } 2017 \\
\text { Available Online: } \\
\text { 10 July } 2017\end{array}$ & \\
\hline
\end{tabular}

\section{Introduction}

Indigenous technical knowledge is unique, traditional, local knowledge existing within and developed around the specific conditions of women and men indigenous to a particular geographical area which is unique among the people and community ${ }^{1}$.

This traditional knowledge is either used for management of different animals and diseases in fields or development of special storage structure or methods of long term storage in home yards ${ }^{2}$.

These have evolved through regular experimentation on the day to day life and available resources surrounded by a family or community. Assam is an agriculture dependent state where more than $70 \%$ of the people engaged in agriculture ${ }^{3}$ and various activities are found to be rationally sound in the farmer's field. The recent step towards ever green revolution to the ecologically sound areas like the North Eastern states of India has given immense importance to the traditional knowledge for development of packages for pest and disease management.

This paper is compilation of unique ITK's practices by the farmers of Assam and also relevance to some parts of North East India. 


\section{Materials and Methods}

The study was carried out in 2 districts viz., Nagaon $\left(26.3464^{\circ} \mathrm{N}, \quad 92.6840^{\circ}\right.$ E) and Morigaon $\left(26.2600^{\circ} \mathrm{N}, 92.2630^{\circ} \mathrm{E}\right)$. Nine villages from each of the districts were selected randomly for the study thus making a total of 18 villages. From each village 10 numbers of farmers of varied age groups of 45-60 years were selected randomly forming a sample size of 180 respondents. Data for the study were collected by using participatory rural appraisal (PRA), group discussion and interview with groups or individuals with the respondent. PRA included the semi-structured interview, group discussions, transect walk with the farmer's group of the selected villages. After identifying, the traditional practices are coded and all the information collected through PRA were analyzed.

\section{Results and Discussion}

The experience of the farmers has led to the development of Indigenous technical knowledge which involves innovative practices and the successful ITK's are transmitted from generations to generations. Some of the modern agricultural practices are evolved from the prevailing indigenous practices in a farming community.

The ITK varies from one geographical region to another based on its suitability and acceptability among the farmers ${ }^{4}$. The prevalent ITK of the two districts in the studied village are as follows:

\section{Pulses storage structure}

The Central Brahmaputra valley zone contributes the major portion of pulses for the state But the pulse growers faces the problem of storage of seeds because the seeds retain higher moisture content due to its size. The villagers have developed their own way of storing the harvested sundried seeds. The structure is built with bamboo or wood, locally called as Bhoral generally used for storage of rice. The structure is filled with the husk of rice or wheat and pulse seed then the bags are tighten in jute bags and kept inside the structure. This helps in safeguarding the seeds from different rodent and pest. And the husk absorbs the moisture from the seeds which helps in preserving the seeds from disease problems.

\section{Oilseeds and pulses storage}

The stored grains of cereals/oilseeds/pulses are easily damaged by pest and diseases if not stored properly. The seeds are stored in earthen pot and about 10-12 cm layer of sand are filled above the grains. Instead of earthen pots, the tin pots can be used for the same but while using the tin pots a thin layer of sand of about $5 \mathrm{~cm}$ should be applied before storing the grains.

\section{Storage of onions, garlic, potato}

The onions, garlic, potato after harvesting can be stored for longer duration. The harvested uncleaned onions and potato are collected in a bamboo sieve and then the sieve is kept over a firewood chulah at least 8 feet above. This helps in preservation for upto 7 months.

\section{Storage of pumpkin and pomelo}

The completely ripened pumpkin and pomelo can be stored for longer duration by applying mustard oil over the surface of the pumpkin or pomelo. Then the fruit is sundried for two days and kept over a Smoked chullah. This increases the shelf life of both the fruit.

\section{Rice storage}

After drying of rice seeds, bagging is done and these bags are kept in alternate rows of rapeseed seeds bags while storing. This helps is reducing the rice storage grain pest. A bulk of leaves of Posotia (Vitexnegundo) or commonly known as horseshoe vitex are hanged in the storage structure of rice. The smell from the leaves of Posotia acts as a repellent against the insect pest of rice. 


\section{Elephant repellent}

In some of the places at Nagaon, during night time the elephants destroy the whole farm lands and home yards. To control these wild elephants, farmers tie white polybags in a string and cover the particular area with those polythene tied strings, the elephants get scared of the movement of white polybags at night and they move away.

\section{Water harvesting}

Water scarcity during dry spell is a common problem. So, the farmers dig a deep small portion of the crop field and allow the rain water to get stored at those areas. When there is water scarcity problem in rice fields, then they irrigate their crop lands using that stored water. Though it doesn't stays for long but it can provide water at peak period.

\section{Rice gundhi bug repellent}

To prevent the infestation of gundhi bug (Leptocoris aacuta), the farmers collect few numbers of gundhi bug from the field and make a paste of the gundhi bug. This paste is mixed with water and sprinkled over the rice fields so that the smell of gundhi bug act as a repellent for gundhi bug itself.

\section{Stem borer repellent}

During the time of field preparation of Sali rice, the farmers sow colocasia in the bunds of rice field. When the rice crop attains vegetative stage, then the farmers chop the colocasia stem and throw into the chopped stems into the main field of the crop. The chemical constituents of colocasia will help in reducing the damage caused by stem borer (Scirpophaga incertulas).
In conclusion, the preservation of our rich culture and wealth is very important since they are the original source of our traditional knowledge. These ITKs are cost effective and easily available with lesser or no-side effects. However, the above described ITKs are being found effective as per observation and discussion made with the farmers but the scientific intervention is still necessary to isolate the important points from the information provided. The study is confined to Central Brahmaputra Valley Zone, but a general study with scientific implications is still required for proper adoption.

\section{Acknowledgement}

The authors are grateful to the Dr. H. C. Bhattacharyya, Director of Extension Education, Assam Agricultural University and Dr. N. Deka, Head of Krishi Vigyan Kendra, Nagaon, Assam for their immense support. Authors also wish to express their sincere gratitude to the villagers of Nagaon and Morigaon for providing valuable informations.

\section{References}

Costa, E. M., 2000 Sustainable development and traditional knowledge: A case study in a Brazilian fishermen's community. Sustainable Dev, 8(2), 89.

Deka, M. K., Bhuyan, M. And Hazarika, L. K., 2006. Traditional pest management practices of Assam, Indian J. Traditional Knowledge, 5(1), 75-78.

Ghosh, P. K. and Sahoo, B., 2011. Indigenous Traditional Knowledge, Orissa Review, 65-70.

Majhi, S. K., 2008. Indigenous technical knowledge for control of insect pest and livestock disorders. Indian $\mathrm{J}$ Traditional Knowledge, 7(3), 463-465.

\section{How to cite this article:}

Gogoi, B., S. Bhagowati and Das, S. 2017. Traditional Crop Management Practices of Central Brahmaputra Valley Zone of Assam. Int.J.Curr.Microbiol.App.Sci. 6(7): 2405-2407. doi: https://doi.org/10.20546/ijcmas.2017.607.284 